Vol 2 No 1 (2019) 70-87 P-ISSN 2620-295 E-ISSN 2747-0490

DOI: $1047467 /$ elmal.v1i1.315

\title{
Pengaruh Reward dan Punishment terhadap Motivasi Kerja Karyawan di PT Antam Tbk UBPE Pongkor Departemen Process Plant
}

\author{
Dudu Badrudin \\ Fakultas Ekonomi \& Bisnis Islam \\ IAI Sahid Bogor \\ Sholikul Hadi \\ SBBC Consulting \\ Rio Kartika Supriyatna \\ Masyarakat Ekonomi Syariah (MES) Boogor
}

\begin{abstract}
Employee work motivation must always be maintained and improved, one way is by implementing rewards and punishments. To improve effective performance, organizational agencies can pay attention to the most important thing, namely meeting the needs of their employees. The objectives of this study include (1) to analyze the effect of reward on employee work motivation (2) to analyze the effect of punishment on work motivation (3) to analyze the effect of reward and punishment on employee motivation at PT Antam Tbk, UBPE Pongkor. The method used in this research is quantitative method with descriptive analytic type of research, data collection is done through a questionnaire, with an active employee population of PT. Antam tbk UBPE pongkor. The method of determining the sample using the tabachic and Fidell method, the number of samples used in this study is 60 PT.Antam.Tbk, UBPE Pongkor employee respondents, the data used and processed is primary data. This study uses multiple linear regression analysis using the statistical package for the social sciencess (spss) version 21 program. Based on the results of statistical calculations, it shows that (1) the reward variable has no positive and not significant effect, (2) the punishment variable has a positive and significant effect (3) the reward and punishment variables together have a significant and significant effect on the work motivation of employees at PT Antam Tbk, UBPE Pongkor.
\end{abstract}

\section{Keywords: Work Motivation, reward and punishment}

\section{ABSTRAK}

Motivasi kerja karyawan harus selalu di pelihara dan di tingkatkan,salah satu caranya adalaha dengan penerapan reward dan punishment untuk meningkatkan kinerja yang efektif, maka instansi organisasi dapat memperhatikan hal yang paling utama yakni pemenuhan kebutuhan pegawainya.Tujuan dari penelitian ini antara lain (1) untuk menganalisa pengaruh reward terhadap motivasi kerja karyawan (2) untuk menganalisa pengaruh punishment terhadapa motivais kerja (3) untuk menganalisa pengaruh reward dan punishment terhadap motivasi kerja karyawan d PT.Antam Tbk, UBPE Pongkor. Metode yang di gunakan dalam penelitian adalah metode kuantitatif dengan jenis penelitian deskriptif analitik, pengumpulan data dilakukan 
Vol 2 No 1 (2019) 70-87 P-ISSN 2620-295 E-ISSN 2747-0490

DOI: $1047467 /$ elmal.v1i1.315

melalui kuesioner, dengan populasi karyawan aktif PT.Antam tbk UBPE pongkor.metode penentuan sempel dengan menggunakan metode tabachic and Fidell, jumlah sampel yang di gunakan penelitian ini 60 responden karyawan PT.Antam.Tbk,UBPE Pongkor data yang di gunakan dan di olah adalah data primer.penelitian ini menggunakan analisis regresi linear berganda dengan menggunakan bantuan program statistical package for the social sciencess(spss) versi 21. Berdasarkan hasil penghitungan statistik menunjukan bahwa (1) variabel reward tidak berpengaruh positif dan tidak nyata, (2) variabel punishment berpengaruh positif dan nyata (3) variabel reward dan punishment secara bersama-sama berpengaruh dan nyata terhadap motivasi kerja karyawan di PT.Antam Tbk,UBPE Pongkor.

\section{Kata Kunci:Motivasi Kerja, reward dan punishment}

\section{PENDAHULUAN}

\section{Latar Belakang Masalah}

Persaingan global telah di mulai, setiap negara mempersiapkan berbagai macam produk, teknologi ,serta Sumber daya manusia yang berkualitas untuk dapat bersaing dengan negara lain, pada tahun 2016 ini komunitas Association of South East Asia Nations telah berlangsung dimana terdapat 10 negara di Asia tenggara dengan tujuan utama yaitu melakukan kerja sama dalam hal Ekonomi Asean, atau di sebut Masyarakat Ekonomi Asean, dan sosial budaya

Namun sejatinya, hal ini tetaplah akan dilihat sebagai persaingan 10 negara yang akan menunjukan kemampuanya masing-masing. perusahaan memiliki peranan penting, banyak pihak yang bergantung dari operasional sebuah perusahaan dalam pemenuhan kebutuhan hidup hal ini membuat setiap perusahaan di tuntut untuk mampu mengelola dengan baik SDM yang dimiliki sebagai alat dalam mencapai tujuan perusahaan.

Salah satu hal yang menjadi concern yaitu pada pilar ekonomi dan pastinya akan merujuk pada pembahasan kemampuan SDM di tiap- tiap negara. Setiap organisasi akan segera berkemas dan menyusun strategi baru dalam manajemennya, tidak kecuali dalam Manajemen Sumber Daya Manusia, (Human Resources Manajemen). Beberapa poin penting yang menjadi aktifitas Manajemen Sumber Daya Manusia yaitu penilaian kinerja atau evaluasi kinerja karyawan untuk melihat kemampuan SDM serta pemberian reward dan punishment untuk menstimulasi dan memotivasi tenaga kerja akan agar lebih bersemangat dan produktif. Poin-poin tersebut akan di bahas dalam penelitian ini dengan tujuan untuk mengetahui bagaimana kontribusinya dalam meningkatkan motivasi kerja karyawan.

Setiap karyawan mempunyai motif tersendiri dalam bekerja dan hampir tidak ada karyawan memiliki motif yang sama. Sebagai karyawan bekerja hanya untuk mendapatkan uang ada yang bekerja karena alasan gengsi dan ada yang bekerja hanya 
Vol 2 No 1 (2019) 70-87 P-ISSN 2620-295 E-ISSN 2747-0490

DOI: $1047467 /$ elmal.v1i1.315

karena tertarik pada jenis pekerjaan tertentu, bahkan mungkin ada beberapa karyawan yang tidak tahu apa yang menjadi motif mereka dalam bekerja.

Motif utama karyawan pada saat ini mungkin akan berubah untuk hari esok. Perubahan motif dalam bekerja ini dapat terjadi kapan saja. setelah satu motif terpenuhi dengan baik sehingga motif yang lain akan menggantikannya. Hal ini menimbulkan perbedaan reaksi terhadap seluruh beban kerja bagi setiap karyawan. Oleh karena itu ada teknik dan strategi yang menjamin bahwa setiap karyawan akan memiliki moral dan disiplin kerja tinggi.

Motivasi kerja di artikan sebagai hasil kerja secara kualitas dan kuantitas yang di capai oleh seorang pegawai negara. MSDM merupakan program, aktivitas untuk mendapatkan, mengembangkan, memelihara dan mendayagunakan SDM untuk mendukung perusahaan mencapai tujuannya. Dalam mencapai tujuan perusahaan, dibutuhkan SDM (karyawan) yang berkualitas.

Kualitas atau motivasi kerja karyawan harus selalu dipelihara dan ditingkatkan, salah satu caranya adalah dengan penerapan reward dan punishment. Untuk meningkatkan kinerja yang efektif, maka instansi organisasi dapat memperhatikan hal yang paling utama yakni pemenuhan kebutuhan pegawainya. Untuk memenuhi kebutuhannya, maka diperlukan adanya imbalan atau kompensasi sebagai bentuk motivasi yang diberikan kepada pegawai. Manajemen kompensasi penting untuk meningkatkan motivasi pegawai mencapai prestasi yang terbaik.

Prinsip penting dalam sistem manajemen kompensasi adalah prestasi yang tinggi harus diberi penghargaan (reward) yang layak dan apabila melanggar aturan dalam organinisasi harus diberikan sangsi yang setimpal serta adil. Kekeliruan dalam menerapkan sistem kompensasi, khususnya sistem penghargaan akan berakibat timbulnya demotivasi dan tidak adanya kepuasan kerja dikalangan pegawai dan apabila hal tersebut terjadi dapat menyebabkan rendahnya motivasi kerja baik pegawai maupun organisasi.

Dalam kenyataannya organisasi menerapkan sistem manajemen kompensasi disesuaikan dengan kondisi masing-masing. Beberapa fakta berikut ini menunjukkan rendahnya sistem reward dan punishment pada sejumlah organisasi bisnis terkemuka didunia menunjukkan bahwa pertumbuhan dan daya kompetitif yang dimiliki dihasilkan melalui kompetensi khusus yang diciptakan melalui pengembangan keterampilan tinggi bagi karyawan, kekhasan kultur organisasi, sistem maupun proses manajemennya.

Menurut Anoraga (2006:35) menjelaskan bahwa motivasi kerja adalah "Sesuatu yang menimbulkan semangat atau dorongan kerja. Oleh sebab itu, motivasi kerja disebut pendorong semangat kerja. Kuat dan lemahnya motivasi kerja seorang tenaga kerja ikut menentukan besar kecilnya prestasinya".

Berdasarkan pendapat Hariandja (2005:156) "Motivasi adalah faktor-faktor yang mengarahkan dan mendorong perilaku atau keinginan seseorang untuk melakukan 
Vol 2 No 1 (2019) 70-87 P-ISSN 2620-295 E-ISSN 2747-0490

DOI: $1047467 /$ elmal.v1i1.315

suatu kegiatan dan dinyatakan dalam bentuk usaha yang keras atau lemah".Motivasi didefinisikan oleh Fillmore H. Stanford dalam Mangkunegara (2002:93) bahwa "Motivasi sebagai suatu kondisi yang menggerakkan manusia ke arah suatu tujuan tertentu".

PT. Antam , Tbk UBPE Pongkor merupakan salah satu perusahaan yang bergerak dalam bidang pertambangan. Dimana reward dan punishment sangat berpengaruh terhadap kinerja karyawan, ini dapat dilihat di Tabel

Tabel 1.1

Absensi Karyawan Tahun 2016

\begin{tabular}{|c|c|c|c|c|c|c|c|}
\hline \multirow{2}{*}{ NO } & \multirow{2}{*}{ BULAN } & \multirow{2}{*}{$\begin{array}{c}\text { JUMLAH } \\
\text { KARYAWAN }\end{array}$} & \multicolumn{5}{|c|}{ KETERANGAN ABSENSI } \\
\hline & & & I & $\mathbf{S}$ & $\mathbf{C}$ & $\mathbf{M}$ & DP \\
\hline 1 & DES-JAN & 125 & - & 1 & 5 & - & $` 1$ \\
\hline 2 & JAN-FEB & 125 & - & 28 & 23 & 2 & - \\
\hline 3 & FEB-MAR & 125 & - & 1 & 5 & - & - \\
\hline 4 & MAR-APR & 125 & - & 2 & 2 & - & 2 \\
\hline 5 & APR-MEI & 125 & - & - & - & - & - \\
\hline 6 & MEI-JUN & 125 & - & 2 & 9 & - & - \\
\hline 7 & JUN-JUL & 125 & - & - & 1 & - & - \\
\hline 8 & JUL-AUG & 125 & - & - & 2 & - & - \\
\hline 9 & AUG-SEPT & 125 & - & 5 & 37 & - & - \\
\hline 10 & SEPT-OKT & 125 & - & - & 4 & - & - \\
\hline 11 & OKT-NOV & 125 & - & - & 2 & - & - \\
\hline 12 & NOV-DES & 125 & - & 2 & - & - & - \\
\hline \multicolumn{3}{|c|}{ TOTAL JUMLAH } & - & 45 & 105 & 2 & 7 \\
\hline
\end{tabular}

Sumber : Data Sekunder, PT. ANTAM (PERSERO), TBK UBPE PONGKOR, 2016

Untuk itu perusahaan harus memikirkan dengan cermat dalam upaya penyediaan sarana dan prasarana yang dibutuhkan, untuk mempermudah kerja karyawan. Sebab keberhasilan karyawan dalam menjalani aktivitasnya tidak terlepas dari masalah reward dan punishment, yang tersedia dan memadai. Berdasarkan hal-hal tersebut maka penelitian ini mengangkat judul. 
Vol 2 No 1 (2019) 70-87 P-ISSN 2620-295 E-ISSN 2747-0490

DOI: $1047467 /$ elmal.v1i1.315

\section{"PENGARUH REWARD DAN PUNISHMENT TERHADAP MOTIVASI KERJA KARYAWAN DI PT. ANTAM (PERSERO), TBK UBPE PONGKOR DEPARTEMEN PROCESS PLANT".}

Tujuan penelitian ini sebagai berikut

1. Untuk menganalisa pengaruh reward terhadap motivasi kerja karyawan di PT. Antam, Tbk UBPE Pongkor.

2. Untuk menganalisa pengaruh punishment terhadap motivasi kerja karyawan di PT. Antam, Tbk UBPE Pongkor.

3. Untuk menganalisa pengaruh reward dan punishment terhadap motivasi kerja karyawan di PT. Antam, Tbk UBPE Pongkor.

\section{METODOLOGI PENELITIAN}

\section{Kerangka Pemikiran}

Berdasarkan uraian teoritis maka dapat digambarkan suatu kerangka pemikiran yang menyatakan bahwa reward dan punishment berpengaruh terhadap kinerja karyawan. Oleh karena itu kerangka pemikiran teori dari penelitian ini adalah sebagai berikut:

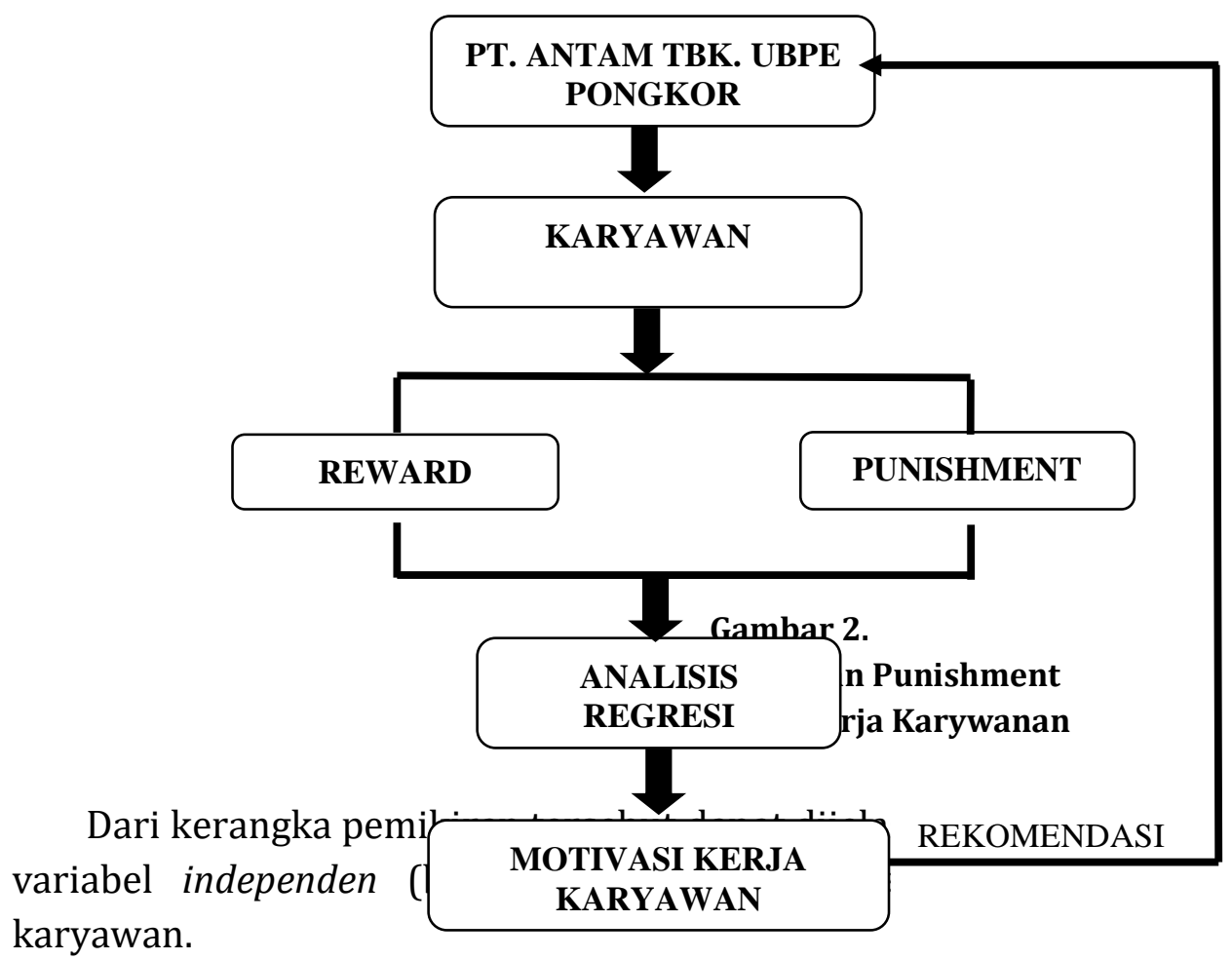

1 punisment lah kinerja

Berdasarkan kerangka pemikiran tersebut, penelitian melihat penerapan reward dan punisment yang diterapkan secara adil dan konsisten akan berdampak kepada motivasi kerja karyawan, demikian pula sebaliknya apabila penerapan reward dan 
Vol 2 No 1 (2019) 70-87 P-ISSN 2620-295 E-ISSN 2747-0490

DOI: $1047467 /$ elmal.v1i1.315

punisment tidak mencerminkan keadilan dan tidak konsisten, maka akan berdampak kepada dismotivasi kerja karyawan. Penelitian ini bertujuan menganalisis kedua variabel independen (bebas) tersebut mempunyai pengaruh terhadap kinerja karyawan secara parsial maupun simultan.

\section{Tempat dan Waktu}

Penelitian ini dilakukan di PT. Pongkor Tbk. UBPE pongkor dengan waktu 2 bulan dari Juli-Agustus 2017.

\section{Sifat Penelitian}

Penelitian ini menggunakan metodologi penelitian kuantitatif yaitu metodologi yang berdasarkan data dari hasil pengukuran berdasarkan variabel penelitian yang ada. Objek kajian dari metodologi penelitian kuantitatif adalah ilmu eksak atau ilmu pasti. Ada dua format penelitian kuantitatif berdasarkan paradigma dominan dalam metodologi penelitian kuantitatif yaitu format deskriptif dan format eksplanasi.

\section{HASIL DAN PEMBAHASAN}

\section{Gambaran Umum Perusahaan}

PT. ANTAM Tbk. (Persero) adalah salah satu Badan Usaha Milik Negara (BUMN). Saat ini PT. Aneka Tambang mempunyai 6 Unit Bisnis Produksi yang salah satunya adalah Unit Bisnis Pertambangan Emas Pongkor. PT. ANTAM Tbk. terletak di Gunung Pongkor. Desa Nunggul, Kecamatan Nanggung Kabupaten Bogor. Daerah ini dapat ditempuh sekitar 54 KM ke arah Barat Daya dari kota Bogor. Luas Kuasa Pertambangan (KP) 6.047 Hektar.Sejarah keberadaan Tambang Emas Pongkor dimulai dengan dilakukannya ekplorasi logam dasar ( $\mathrm{Pb}$ dan $\mathrm{Zn}$ ) di bagian Utara Gunung Pongkor oleh para Geologiwan Aneka Tambang pada tahun 1974 sampai 1981. Survey pendahuluan yang dilakukan pada tahun 1981 di daerah Pongkor menemukan endapan urat Kwarsa (quart vein) berkadar 4 gpt (gram per ton) emas dan 126 gpt (gram per ton) perak. Karena Aneka Tambang sedang memfokuskan pada kegiatan ekplorasi di sekitar Tambang Cikotok, maka antara tahun 1983 - 1988 kegiatan ekplorasi di Pongkor ditangguhkan, baru pada tahun 1988 - 1991 dilanjutkan kembali dengan lebih sistematis dan lengkap. Studi kelayakan kemudian dibuat dan Kuasa Pertambangan Eksploitasi yang pertama dengan nomor KP. DU 893/Jabar seluas 4.058 Ha diperoleh pada tahun 1991. Jalan masuk ke Pongkor sepanjang 12,5 km dibangun pada tahun 1992 bekerjasama dengan ABRI dalam Program/Proyek AMD (ABRI Masuk Desa). Pada tahun 1993 dibangun pabrik yang pertama dengan kapasitas 2,5 ton emas/tahun. Pada tahun yang sama dibangun pula Tailing Dam. Pada tahun 1994 dilakukan Commisioning Pabrik Pengolahan Emas dan kemudian Proyek Tambang Emas Pongkor resmi menjadi Unit Pertambangan Emas Pongkor. Tahun 1997 dilakukan pengembangan tambang di daerah Ciurug, penambangan disini dilakukan dengan sistem mekanis. Pabrik yang kedua dibangun sehingga kapasitas produksi menjadi 5 ton emas/tahun. 
Vol 2 No 1 (2019) 70-87 P-ISSN 2620-295 E-ISSN 2747-0490

DOI: $1047467 /$ elmal.v1i1.315

\section{Karakteristik Responden}

Penelitian mengenai pengaruh reward dan punishment terhadap motivasi kerja karyawan di ptantam (persero),tbk ubpe pongkor departemen process plant, menggunakan responden sebanyak 60 orang karyawan antam pongkor. Dari 125 kuesioner yang diberikan kepada karyawan, mngembalikan 60 dan sisa yang tertinggal 65 kuesioner. Terdapat lima karakteristik responden yang dimasukan dalam penelitian, yaitu berdasarkan jenis kelamin, status, usia, pendidikan,jabatan dan masa kerja. Untuk memperjelas karakteristik responden yang dimaksud, maka disajikan tabel mengenai responden seperti dijelaskan berikut ini.

\section{Jenis Kelamin}

Jenis kelamin responden yang diambil sebagai responden, yaitu sebanyak 60 orang dan seluruhnya berjenis kelamin laki-laki

\section{Usia Responden}

Jumlah responden dalam penelitian ini dikelompokan berdasarkan usia dengan rincian sebagai berikut:

Tabel 5.

Responden Berdasarkan Usia

\begin{tabular}{|l|c|c|}
\hline \multicolumn{1}{|c|}{ Usia } & Jumlah & Persentase (\%) \\
\hline $21-30$ & 13 & $22 \%$ \\
\hline $31-40$ & 22 & $36 \%$ \\
\hline $41-50$ & 25 & $42 \%$ \\
\hline $45-55$ & - & - \\
\hline$>55$ & - & - \\
\hline Total & 60 & $100 \%$ \\
\hline
\end{tabular}

Sumber: Olah Data Primer, 2017

Berdasarkan Tabel diatas dapat diketahui bahwa, mayoritas usia responden 31-40 tahun adalah 36\% atau 22 orang, dan paling sedikit berada di kisaran 2130 tahun sebanyak 22 orang atau $22 \%$.

\section{Jabatan}

Jumlah responden dalam penelitian ini berdasarkan pekerjaan dapat dilihat pada tabel berikut:

Tabel 6.

Responden Berdasarkan Jabatan

\begin{tabular}{|l|c|c|}
\hline \multicolumn{1}{|c|}{ Jabatan } & Jumlah & Persentase (\%) \\
\hline Manager & 1 & $2 \%$ \\
\hline Assisant Manager & 2 & $4 \%$ \\
\hline Staff & 5 & $8 \%$ \\
\hline Admin & 1 & $2 \%$ \\
\hline Supervisor & 8 & $13 \%$ \\
\hline Operator & 43 & $71 \%$ \\
\hline
\end{tabular}


Vol 2 No 1 (2019) 70-87 P-ISSN 2620-295 E-ISSN 2747-0490

DOI: $1047467 /$ elmal.v1i1.315

\begin{tabular}{|l|c|c|}
\hline Total & 60 & $100 \%$ \\
\hline
\end{tabular}

Sumber: Olah Data Primer, 2017

Dari table di atas dapat diketahui bahwa responden yang memilki jabatan sebagai operator menjadi mayoritas responden sebanyak 43 orang atau $71 \%$, sedangkan yang paling sedikit menjabat sebagai manajer dan admin sebanyak masing-masing 1 orang atau $2 \%$.

\section{Pendidikan}

Jumlah responden dalam penelitian ini berdasarkan pendidikan terakhir dapat dilihat pada tabel berikut:

Tabel 7.

Responden Berdasarkan Pendidikan

\begin{tabular}{|l|c|c|}
\hline \multicolumn{1}{|c|}{ Pendidikan } & Jumlah & $\begin{array}{c}\text { Persentase } \\
\text { (\%) }\end{array}$ \\
\hline SD & - & - \\
\hline SMP & 8 & $13 \%$ \\
\hline SMA & 39 & $65 \%$ \\
\hline Diploma & 3 & $6 \%$ \\
\hline S.1 & 10 & $16 \%$ \\
\hline S.2 & - & - \\
\hline Total & 60 & $100 \%$ \\
\hline
\end{tabular}

Sumber: Olah Data Primer, 2017

Berdasarkan Tabel diatas dapat diketahui responden berdasarkan pendidikan terakhir, menunjukan bahwa pendidikan terakhir responden mayoritas adalah SMA sebanyak $65 \%$ atau 39 orang dan paling sedikit adalah SMP sebanyak 13 orang atau $13 \%$.

\section{Masa Kerja}

Jumlah responden dalam penelitian ini berdasarkan masa kerja karyawan, dapat dilihat pada tabel berikut:

Tabel 8.

Responden Berdasarkan Masa Kerja

\begin{tabular}{|l|c|c|}
\hline \multicolumn{1}{|c|}{ Masa Kerja } & Jumlah & $\begin{array}{c}\text { Persentase } \\
\text { (\%) }\end{array}$ \\
\hline 1-5 Tahun & 3 & $2 \%$ \\
\hline 5-10 Tahun & 3 & $2 \%$ \\
\hline 10-15 Tahun & 6 & $10 \%$ \\
\hline 15-20 Tahun & 30 & $50 \%$ \\
\hline 20-25 Tahun & 12 & $20 \%$ \\
\hline Total & 60 & $100 \%$ \\
\hline
\end{tabular}

Sumber: Olah Data Primer, 2017 
Vol 2 No 1 (2019) 70-87 P-ISSN 2620-295 E-ISSN 2747-0490

DOI: $1047467 /$ elmal.v1i1.315

Berdasarkan Tabel diatas dapat diketahui responden berdasarkan masa kerja, menunjukan bahwa masa kerja adalah 1-5 tahun dan 5-10 tahun sebesar $2 \%$ atau 3 orang menjadi responden yang paling sedikit, sedangkan yang masa kerja 15-20 menjadi mayoritas responden sebanyak 50\% atau 30 orang.

\section{Uji Validitas dan Reliabilitas}

Dalam penelitian ini dilakukan terlebih dahulu uji validitas per item pertanyaan sebelum dilakukan analisis lebih lanjut. Uji validitas dan reliabilitas dilakukan dengan menggunakan software IBM SPSS Statistics 21. Dalam uji validitas dan reliabilitas peneliti menggunakan jumlah sampel sebanyak 60 responden. Berikut adalah tabel uji validitas dan reliabilitas.

\section{Hasil Uji Validitas dan Reliabilitas terhadap reward( $\left.X_{1}\right)$}

Hasil uji validitas untuk variabel reward $\left(\mathrm{X}_{1}\right)$ dapat dilihat pada tabel di bawah ini:

Tabel 9.

Tabel Validitas reward

\begin{tabular}{|c|r|c|c|}
\hline $\begin{array}{c}\text { Reward }\left(\mathbf{X}_{\mathbf{1}}\right) \\
\text { Indikator }\end{array}$ & $\begin{array}{c}\text { CorrectedItem- } \\
\text { Total Correlation }\end{array}$ & $\mathrm{r}_{\text {table }}$ & $\begin{array}{c}\text { Keteranga } \\
\mathrm{n}\end{array}$ \\
\hline $\mathrm{X}_{1} \cdot\left(\mathrm{P}_{1}\right)$ &, 612 &, 2542 & Valid \\
\hline $\mathrm{X}_{1} \cdot\left(\mathrm{P}_{2}\right)$ &, 583 &, 2542 & Valid \\
\hline $\mathrm{X}_{1} \cdot\left(\mathrm{P}_{3}\right)$ &, 635 &,, 2542 & Valid \\
\hline $\mathrm{X}_{1} \cdot\left(\mathrm{P}_{4}\right)$ &, 682 &, 2542 & Valid \\
\hline $\mathrm{X}_{1} \cdot\left(\mathrm{P}_{5}\right)$ &, 766 &, 2542 & Valid \\
\hline $\mathrm{X}_{1} \cdot\left(\mathrm{P}_{6}\right)$ &, 503 &, 2542 & Valid \\
\hline $\mathrm{X}_{1} \cdot\left(\mathrm{P}_{7}\right)$ &, 465 &, 2542 & Valid \\
\hline $\mathrm{X}_{1} \cdot\left(\mathrm{P}_{8}\right)$ &, 313 &, 2542 & Valid \\
\hline
\end{tabular}

Sumber: Peneliti, Output IBM SPSS Statistics 21 yang di olah ,2017

Uji validitas data pada penelitian ini dengan membandingkan nilai $r_{\text {hitung }}$ dengan $r$ tabel pada taraf kepercayaan $95 \%$ atau signifansi $5 \%(\alpha=0,05)$ dapat dicari berdasarkan jumlah responden atau N. Karena N =60, maka derajat bebasnya adalah N-2=60-2 = 58 . Nilai $r$ tabel pada $\mathrm{df}=58$ dan $\alpha=0,05$ adalah 0,2542. Dari hasil analisis diperoleh $r$ hitung pada variabel rewadr $>r$ table, maka item pertanyaan tersebut dikatakan valid.

Dari delapan pernyataan diatas semua pernyataan valid dengan demikian semua pernyataan pada kuesioner untuk variabel reward, dan dapat digunakan dalam penelitian selanjutnya. 
Vol 2 No 1 (2019) 70-87 P-ISSN 2620-295 E-ISSN 2747-0490

DOI: $1047467 /$ elmal.v1i1.315

Selanjutnya, untuk menguji reliabilitas dari instrumen penelitian dikatakan reliabel jika nilai $\alpha \geq 0.6$ (Nunnally dalam Imam Ghozali 2013:48), sehingga data dapat digunakan sebagai bahan penelitian untuk analisis data. Berdasarkan hasil pengolahan data pada software SPSS 21 hasil pengujian reliabilitas yang diperoleh tabel di bawah ini:

Tabel 10.

Hasil Uji Reliabilitas pada reward $\left(\mathrm{X}_{1}\right)$

\section{Reliability Statistics}

\begin{tabular}{|r|c|c|}
\hline \multicolumn{1}{|c|}{ Cronbach's Alpha } & $\begin{array}{c}\text { Cronbach's Alpha Based } \\
\text { on Standardized Items }\end{array}$ & N of Items \\
\hline, 828 & .693 & 8 \\
\hline
\end{tabular}

Sumber: Peneliti, Output IBM SPSS Statistics 21yang di olah,2017

Berdasarkan hasil perhitungan di atas, dapat dikatakan bawa instrumen penelitian menunjukan reliabel, karena nilaiCronbach's Alpha0.693>0,6. Jadi instrumen penelitian dinyatakan dapat digunakan.

\section{Hasil Uji Validitas dan Reliabilitas pada punishment $\left(\mathrm{X}_{2}\right)$}

Hasil uji validitas untuk variabel punishment $\left(\mathrm{X}_{2}\right)$ dapat dilihat pada tabel di bawah ini:

Tabel 11. Tabel Validitas pada punishment $\left(X_{2}\right)$

\begin{tabular}{|c|c|c|c|}
\hline $\begin{array}{l}\text { punishment }\left(\mathrm{X}_{2}\right) \\
\text { Indikator }\end{array}$ & $\begin{array}{c}\text { Corrected } \\
\text { Item-Total } \\
\text { Correlation }\end{array}$ & $\mathrm{r}$ tabel & Keterangan \\
\hline $\mathrm{X}_{2 .}\left(\mathrm{P}_{9}\right)$ & ,624 & ,2542 & Valid \\
\hline $\mathrm{X}_{2 .}\left(\mathrm{P}_{10}\right)$ &, 556 & 2542 & Valid \\
\hline $\mathrm{X}_{2 \cdot} \cdot\left(\mathrm{P}_{11}\right)$ & ,150 & ,2542 & Tidak Valid \\
\hline $\mathrm{X}_{2 \cdot} \cdot\left(\mathrm{P}_{12}\right)$ & 427 & ,2542 & Valid \\
\hline $\mathrm{X}_{2 \cdot} \cdot\left(\mathrm{P}_{13}\right)$ & 382 & ,2542 & Valid \\
\hline $\mathrm{X}_{2 .}\left(\mathrm{P}_{14}\right)$ & 631 & ,2542 & Valid \\
\hline $\mathrm{X}_{2 \cdot} \cdot\left(\mathrm{P}_{15}\right)$ & 491 & ,2542 & Valid \\
\hline $\mathrm{X}_{2 .}\left(\mathrm{P}_{16}\right)$ & 415 & ,2542 & Valid \\
\hline
\end{tabular}

Dari delapan pernyataan diatas ada satu pernyataan yang tidak valid yaitu $\mathrm{P}_{11}$, dengan demikian ada tujuh pernyataan pada kuesioner untuk variabel $\mathrm{X}_{2}$, dan dapat digunakan dalam penelitian selanjutnya.

Untuk menguji reliabilitas dari instrumen penelitian dikatakan reliabel jika nilai $\alpha$ $\geq 0.6$ (Nunnally dalam Imam Ghozali 2013:48), sehingga data dapat digunakan sebagai bahan penelitian untuk analisis data. Berdasarkan hasil pengolahan data pada software SPSS 21 hasil pengujian reliabilitas yang diperoleh tabel di bawah ini:

Tabel 12.

Hasil Uji Reliabel pada punishment $\left(\mathrm{X}_{2}\right)$ 
Vol 2 No 1 (2019) 70-87 P-ISSN 2620-295 E-ISSN 2747-0490

DOI: $1047467 /$ elmal.v1i1.315

\begin{tabular}{|c|c|c|}
\hline Cronbach's Alpha & $\begin{array}{l}\text { Cronbach's Alpha Based on } \\
\text { Standardized Items }\end{array}$ & $\mathrm{N}$ of Items \\
\hline ,790 & .741 & 8 \\
\hline
\end{tabular}

Sumber: Peneliti, Output IBM SPSS Statistics 21 yang di olah, 2017

Berdasarkan hasil perhitungan di atas, dapat dikatakan bawa instrumen penelitian menunjukan reliabel, karena nilai Cronbach's Alpha 0.790>0,6. Jadi instrumen penelitian dinyatakan dapat digunakan.

\section{Hasil Uji Validitas dan Reliabilitas pada motivasi kerja (Y)}

Hasil uji validitas untuk variabel motivasi Kerja (Y) dapat dilihat pada tabel dibawah ini:

Tabel 15.

Hasil Uji Validitas pada motivasi Kerja (Y)

\begin{tabular}{|c|c|c|c|}
\hline $\begin{array}{l}\text { Motivasi } \\
\text { Kerja (Y) } \\
\text { Indikator }\end{array}$ & $\begin{array}{l}\text { Corrected Item- } \\
\text { Total Correlation }\end{array}$ & $\mathrm{r}$ table & Keterangan \\
\hline $\mathrm{Y} .\left(\mathrm{P}_{17}\right)$ & ,540 & ,2542 & Valid \\
\hline $\mathrm{Y} .\left(\mathrm{P}_{18}\right)$ & ,215 & ,2542 & Tidak Valid \\
\hline $\mathrm{Y} .\left(\mathrm{P}_{19}\right)$ & 432 & ,2542 & Valid \\
\hline $\mathrm{Y} .\left(\mathrm{P}_{20}\right)$ & ,561 & ,2542 & Valid \\
\hline $\mathrm{Y} .\left(\mathrm{P}_{21}\right)$ & 419 & ,2542 & Valid \\
\hline $\mathrm{Y} .\left(\mathrm{P}_{22}\right)$ & 442 &, 2542 & Valid \\
\hline $\mathrm{Y} .\left(\mathrm{P}_{23}\right)$ & ,297 & ,2542 & Valid \\
\hline $\mathrm{Y} .\left(\mathrm{P}_{24}\right)$ & ,412 & 2542 & Valid \\
\hline
\end{tabular}

Sumber: Peneliti, Output IBM SPSS Statistics 21 yang di olah, 2017

Dari delapan pernyataan diatas ada satu pernyataan yang tidak valid yaitu P18,dengan demikian ada tujuh pernyataan pada kuesioner untuk variabel $Y$, dan dapat digunakan dalam penelitian karena ketujuh pernyataan tersebut memilikinilai $r$ hitung $>r$ tabel pada varial Y.

Selanjutnya, untuk menguji reliabilitas dari instrumen penelitian dikatakan reliabel jika nilai $\alpha \geq 0.6$ (Nunnally dalam Imam Ghozali 2013:48), sehingga data dapat digunakan sebagai bahan penelitian untuk analisis data. Berdasarkan hasil pengolahan data pada software SPSS 21 hasil pengujian reliabilitas yang diperoleh tabel di bawah ini:

Tabel 16.

Hasil Uji Reliabilitas pada motivasi Kerja

\begin{tabular}{|c|c|c|}
\hline Cronbach's Alpha & $\begin{array}{c}\text { Cronbach's Alpha Based on } \\
\text { Standardized Items }\end{array}$ & N of Items \\
\hline, 760 & .712 & 8 \\
\hline
\end{tabular}

Sumber: Peneliti, Output IBM SPSS Statistics 21 yang diolah,2017 
Vol 2 No 1 (2019) 70-87 P-ISSN 2620-295 E-ISSN 2747-0490

DOI: $1047467 /$ elmal.v1i1.315

Berdasarkan hasil perhitungan di atas, dapat dikatakan bawa instrumen penelitian menunjukan reliabel, karena nilai Alpha Cronbach's $0.663>0,6$. Jadi instrumen penelitian dinyatakan dapat digunakan.

\section{Uji Asumsi Klasik}

\section{Uji Normalitas}

Uji normalitas bertujuan untuk menguji apakah dalam model regresi, variabel terikat dan variabel bebas keduanya mempunyai distribusi normal atau tidak. Model regresi yang baik adalah memiliki distribusi data normal atau mendekati normal. Hasil uji normalitas secara grafik Probability Plot dengan menggunakan SPSS versi 21 untuk variabel motivasi kerja ditunjukkan dengan grafik dibawah ini.

Normal P-P Plot of Regression Standardized Residual

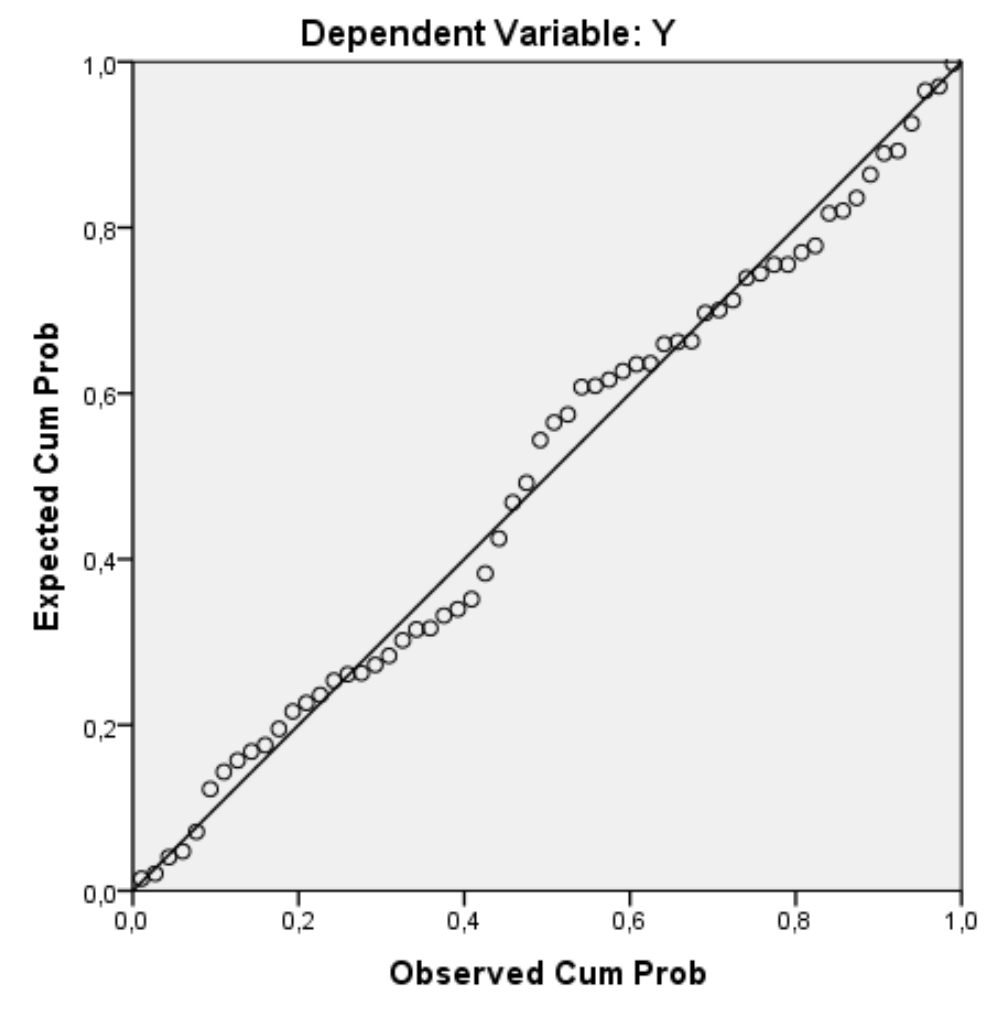

Gambar 3. Normal P-Plot

Sumber : Output IBM SPSS Statistik 21 yang diolah, 2017

Berdasarkan tampilan grafik Normal P-Plot diatas, dapat disimpulkan bahwa pola grafik normal terlihat dari titik-titik yang menyebar disekitar garis diagonal dan penyebarannya mengikuti arah garis diagonal. Berdasarkan grafik normal plot, menunjukkan bahwa model regresi layak dipakai dalam penelitian ini karena memenuhi asumsi normalitas.

\section{Uji Multikolonieritas}

Uji multikoloinearitas bertujuan untuk menguji apakah model regresi memiliki korelasi antara variabel independen atau tidak. Model regresi yang baik seharusnya tidak memiliki korelasi antara 


\section{Cl, Pl/TIV | Jurnal Kajian Ekonomi \& Bisnis Islam}

Vol 2 No 1 (2019) 70-87 P-ISSN 2620-295 E-ISSN 2747-0490

DOI: $1047467 /$ elmal.v1i1.315

variabel independen. Untuk mengukur uji multikolinearitas dapat dilihat darinilai tolerance dan Variance Inflation Factor (VIF) dihitung dengan menggunakan IBM SPSS Statistics 21 diperoleh:

Tabel 18.

Hasil Uji Multikolonieritas

\begin{tabular}{|l|r|r|l|}
\hline \multicolumn{1}{|c|}{ Variabel } & \multicolumn{1}{|c|}{ Tolerance } & \multicolumn{1}{c|}{ VIF } & Keterangan \\
\hline Reward (X1) &, 905 & 1,105 & Tidak terjadi multikolonieritas \\
\hline Punishment (X2) &, 905 & 1,105 & Tidak terjadi multikolonieritas \\
\hline
\end{tabular}

Sumber: Peneliti, Output IBM SPSS Statistics 21 yang di olah,2017

Menurut Imam Ghazali (2013: 105) nilai cutoff yang umum dipakai untuk menunjukan adanya multikolonieritas adalah jika nilai tolerance $<0.10$ atau sama dengan nilai VIF $>10$. Berdasarkan hasil perhitungan variabel independen (otoriter, demokrasi, dan bebas) dari Variance Inflation Factor (VIF) menunjukan tidak ada variabel independenyang memiliki nilai VIF $>10$, jadi dapat disimpulkan tidak ada multikolinearitas antar variabel independen dalam model regresi.

\section{Uji Heteroskedastisitas}

Untuk mendeteksi ada atau tidaknya heteroskedastisitas yaitu dengan melihat grafik Plot antara nilai prediksi variabel terikat (dependen) yaitu ZPRED dengan residualnya SRESID. Uji heteroskedastisitas dapat dilakukan dengan melihat ada tidaknya pola tertentu pada grafik scatterplot antara SRESID dan ZPRED dimana sumbu Y adalah Y yang telah diprediksi, dan sumbu $\mathrm{X}$ adalah residual. Dasar analisisnya adalah sebagai berikut:

\section{Scatterplot}

Dependent Variable: $Y$

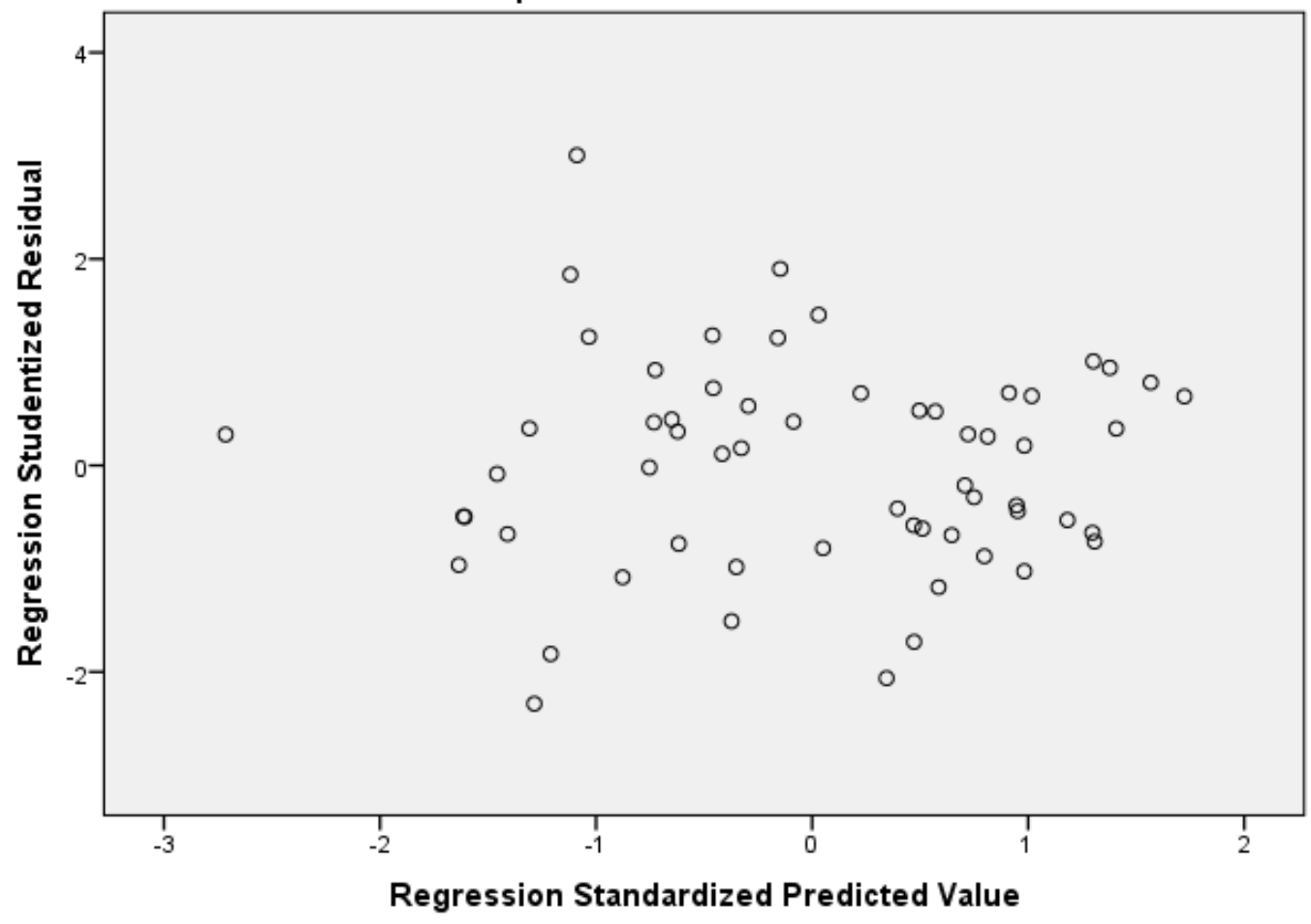

Gambar 4. Uji Heteroskedastisitas 
Vol 2 No 1 (2019) 70-87 P-ISSN 2620-295 E-ISSN 2747-0490

DOI: $1047467 /$ elmal.v1i1.315

Berdasarkan grafikscatterplotdapat dilihat bahwa titik-titik menyebar secara acak di atas dan di bawah nilai $\mathrm{Y}=0$. Berdasarkan grafik scatterplot, peneliti dapat menarik kesimpulan bahwa tidak ada heteroskedastisitas pada model regresi, sehingga model regresi layak digunakan.

\section{Uji Autokolerasi}

Autokorelasi pada model regresi artinya ada korelasi antar anggota sampel yang diurutkan berdasarkan waktu saling berkorelasi. Untuk mengetahui adanya autokorelasi dalam suatu model regresi dilakukanmelalui pengujian terhadap nilai uji Durbin Watson (Uji DW) dengan ketentuan sebagai berikut (Algifari, 2000) :

$\mathrm{DL}=1,4797$

$\mathrm{DU}=1,6889$

Kurang 1,4797 = Ada autokorelasi

$1,4797 \mathrm{~s} / \mathrm{d} 1,6889=$ Tanpa kesimpulan

$1,6889 \mathrm{~s} / \mathrm{d} 2,3111=$ Tidak ada autokorelasi

2,3111 s/d 3,213= = Tanpa kesimpulan

Lebih dari 3,213= = Ada autokorelasi

Tabel 19. Hasil Uji Autokorelasi DW

\begin{tabular}{|l|r|r|r|r|r|}
\hline Model & \multicolumn{1}{|c|}{$\mathrm{R}$} & R Square & Adjusted R Square & $\begin{array}{c}\text { Std. Error of the } \\
\text { Estimate }\end{array}$ & Durbin-Watson \\
\hline 1 &, $630^{\text {a }}$ &, 397 &, 376 &, 40209 & 1,819 \\
\hline
\end{tabular}

Sumber: Peneliti, Output IBM SPSS Statistics 21 yang di olah,2017

Dari hasil data di atas dapat dijelaskan model nilai DW sebesar 1.819. Jadi, dapat disimpulkan bahwa tidak ada autokorelasi pada model regresi.

\section{F. UJI HIPOTESIS}

1. Uji Koefisien Determinan

Untuk mengetahui hubungan antara dua atau lebih variable independen dengan satu variable dependen (otoriter, demokrasi dan bebas), akan dihitung menggunakan software IBM SPSS Statistics 21 sebagai berikut

Tabel 21.Hasil Uji Koefisien Determinan

\begin{tabular}{|c|c|c|c|c|}
\hline Model & $\mathrm{R}$ & R Square & Adjusted R Square & Std. Error of the Estimate \\
\hline
\end{tabular}


Vol 2 No 1 (2019) 70-87 P-ISSN 2620-295 E-ISSN 2747-0490

DOI: $1047467 /$ elmal.v1i1.315

\begin{tabular}{|c|c|c|c|c|}
\hline 1 &, $630^{\mathrm{a}}$ &, 397 &, 376 & 40209 \\
\hline
\end{tabular}

Sumber: Output IBM SPSS Statistics 21 yang di olah, 2017

Nilai $R$ Square $=0.397$ atau 39,7\%. Hal ini berarti bahwa variable independen (Reward, Punishment) mempengaruhi variabel dependen (Motivasi Kerja) dengan nilai 39,7\%, sedangkan sisanya $60,3 \%$ dipengaruhi oleh faktor lain yang tidak dalam penelitian diluar dua variabel yang diteliti.

\section{Pengujian Signifikasi Parameter Individual (Uji t)}

Uji t dilakukan untuk mengetahui pengaruh masing-masing variabel bebas yang terdiri dari reward dan punishment terhadap variabel terikat motivasi kerja. Dapat ditunjukkan pada tabel sebagai berikut:

Tabel 22. Hasil Uji Regresi Liniear Berganda dan Uji Statistik t

\begin{tabular}{|rl|r|r|r|r|r|}
\hline \multicolumn{2}{|l|}{ Model } & \multicolumn{2}{|c|}{ Unstandardized Coefficients } & \multicolumn{1}{c|}{$\begin{array}{c}\text { Standardized } \\
\text { Coefficients }\end{array}$} & \multicolumn{1}{c|}{ Sig. } \\
\cline { 3 - 5 } & (Constant) & B & Std. Error & Beta & & \\
\hline \multirow{2}{*}{1} & 1,059 &, 333 & & 3,178 &, 002 \\
& X1 &, 161 &, 092 &, 190 & 1,759 &, 084 \\
& X2 &, 490 &, 097 &, 545 & 5,040 &, 000 \\
\hline
\end{tabular}

Sumber: Peneliti, Output IBM SPSS Statistics 16 yang di olah,2017

Dari hasil uji parsial pada tabel pengaruh masing-masing variabel reward dan punishment terhadap variabel terikat motivasi kerja dapat dijelaskan sebagai berikut:

a. Variabel Reward $\left(\mathrm{X}_{1}\right)$

Nilai thitung untuk variabel ini sebesar 1,757 dengan nilai tabel dengan uji dua arah dan $\alpha=5 \%$ $(0,05)$ sebesar 1,29632 Hasil uji tersebut menunjukkan dan nilai thitung 1,757>tabel 1,29632. Sehingga dapat disimpulkan bahwa variabel reward $\left(\mathrm{X}_{1}\right)$ secara parsial atau terpisah berpengaruh positif dan nyata terhadap variabel motivasi kerja.Dengan demikian $\mathrm{H}_{\mathrm{a}}$ diterima dan H ditolak.

b. Variabel Punishment $\left(\mathrm{X}_{2}\right)$

Nilai thitung untuk variabel ini sebesar 5,040 dengan nilai tabel dengan uji dua arah dan $\alpha=5 \%$ $(0,5)$ sebesar. Hasil uji tersebut menunjukkan dan nilai thitung 5,040 $>\mathbf{t}_{\text {tabel }} \mathbf{1 , 2 9 6 3 2}$ Sehingga dapat disimpulkan bahwa variabel punishment $\left(\mathrm{X}_{2}\right)$ secara parsial berpengaruhterhadap variabel motivasi. Dengan demikian $\mathrm{H}_{\mathrm{a}}$ diterima dan Ho ditolak. 
Vol 2 No 1 (2019) 70-87 P-ISSN 2620-295 E-ISSN 2747-0490

DOI: $1047467 /$ elmal.v1i1.315

\section{Uji Simultan (uji statistik f )}

Uji F pada dasarnya menunjukkan apakah semua variabel bebas yang dimasukkan dalam model mempunyai pengaruh secara simultan terhadap variabel terikat. Dalam penelitian ini pengujian hipotesis secara simultan dimaksudkan untuk mengukur besarnya pengaruh variabel bebas (Reward dan punishment) terhadap variabel terikat (etos kerja). Hasil uji $\mathrm{F}$ melalui software IBM SPSS Statistics dapat dilihat pada tabel di bawah ini:

Tabel 23. Hasil Uji Statistik F

ANOVAa $^{a}$

\begin{tabular}{|ll|r|r|r|r|r|}
\hline Model & & Sum of Squares & Df & Mean Square & F & Sig. \\
\hline \multirow{2}{*}{1} & Regression & 6,071 & 2 & 3,036 & 18,777 &, $000^{\mathrm{b}}$ \\
& Residual & 9,215 & 57 &, 162 & & \\
& Total & 15,287 & 59 & & & \\
\hline
\end{tabular}

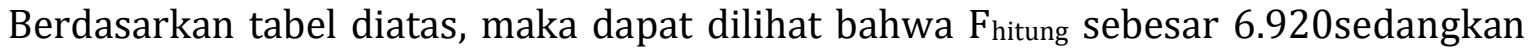
nilai $F_{\text {tabel }}$ distribusi dengan tingkat kesalahan 0,5. Hal ini berarti $F_{\text {hitung }}>F_{\text {tabel }}(18,777>$ 2,42). Perhitungan tersebut menunjukkan bahwa variabel bebas terdiri reward dan punishment, mempunyai pengaruh yang positif dan nyata terhadap variabel motivasi kerja. Maka peneliti menyimpulkan hipotesis penelitian ini yang menyatakan bahwa variabel bebas (reward dan punishment) secara simultan berpengaruh positif dan berpengaruh nyata terhadap variabel terikat motivasi kerja terbukti dan dapat diterima.

\section{Perumusan Model Persamaan Regresi}

Hasil pengujian asumsi klasikyang telah dilakukan, dapat disimpulkan bahwa model regresi dalam penelitian ini layak digunakan. Selanjutnya dapat dilakukan uji estimasi linier berganda dan diinterpretasikan. Berdasarkan output regresi linier pada tabel di atas model regresi berganda yang digunakan dalam penelitian ini dapat dirumuskan sebagai berikut:

$$
\mathrm{Y}=1,864+0,436 \text { reward }+0,102 \text { punishment }+e_{1}
$$

Interpretasi dari analisis regresi:

- Konstanta $(\alpha)=1,864$, artinya jika variabel independen reward $\left(X_{1}\right)$, punishment $\left(X_{2}\right)$, bernilai 0 , maka pengaruh gaya kepemimpinan terhadap motivasi kerja karyawan di PT.Antam adalah 1,864.

- Reward $\left(\mathrm{X}_{1}\right)=0,436$ merupakan nilai koefisien regresi variabel reward $\left(\mathrm{X}_{1}\right)$ terhadap variabel motivasi kerja $(\mathrm{Y})$ artinya jika reward naik satu-satuan, maka motvasi kerja akan mengalami kenaikan sebesar 0.436 koefisien bernilai positif artinya antara reward $\left(\mathrm{X}_{1}\right)$ dan motivasi kerja $(\mathrm{Y})$ hubungan positif. Peningkatan reward $\left(\mathrm{X}_{1}\right)$ akan mengakibatkan peningkatan pada motivasi kerja karyawan( $(\mathrm{Y})$.

- Punishment $\left(\mathrm{X}_{2}\right)=0,102$ merupakan nilai koefisien regresi variabel demokrasi $\left(\mathrm{X}_{2}\right)$ terhadap variabel motivasi kerja (Y)artinya jika reward naik satu-satuan, maka motivasi kerja akan mengalami kenaikan sebesar 0.102 koefisien bernilai positif artinya antara punishmen $t\left(\mathrm{X}_{2}\right)$ dan motivasi kerja $(\mathrm{Y})$ hubungan positif. Peningkatan punishment $\left(\mathrm{X}_{2}\right)$ akan mengakibatkan peningkatan pada motivasi kerja karyawan $(\mathrm{Y})$.

\section{Interpretasi Data}


Vol 2 No 1 (2019) 70-87 P-ISSN 2620-295 E-ISSN 2747-0490

DOI: $1047467 /$ elmal.v1i1.315

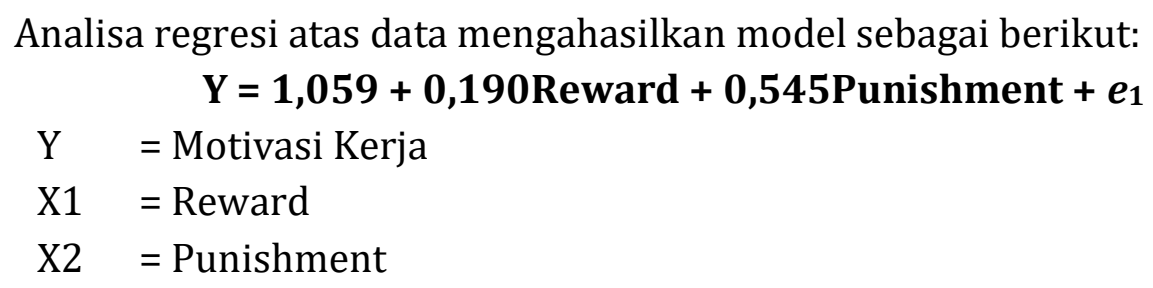

Interpretasi dan pembahasan model yang diperoleh dalam analisis regresi adalah sebagai berikut:

1. Nilai R-Square $\left(R^{2}\right) 0,397$ berarti variabel reward dalam model ini hanya mempengaruhi $39,7 \%$ sedangkan sisanya $60,3 \%$ dipengaruhi oleh variabel lain yang tidak diteliti.Variabel lain yang mempengaruhi diantaranya yaitu upaya, tujuan organisasi dan kebutuhan. (Stephen P. Robbin: 2001).

1. Dari hasil uji F, diperoleh nilai F-hitung 18,777 dengan sig 0,001 ini menjelaskan bahwa semua variabel independen (reward, punishment) secara bersama-sama dapat mempengaruhi motivasi kerja karyawan. Hal ini sesuai dengan penelitian yang dilakukan Yuanita Widianti Sofiana Sari (2014), hasil penelitian ini menunjukan bahwa terdapat pengaruh komunikasi internal, reward dan punishment secara signifikan terhadap motivasi kerja Karyawan PT.Bpr Nur Semesta Indah Kencong Jember dengan arah positif.

2. Uji t

a. Hasil uji t pada variabel reward $\left(\mathrm{X}_{1}\right)$ Sehingga dapat disimpulkan bahwa variabel reward berpengaruh positif dan nyata terhadap motivasi kerja sebab nilai thitung $1,757>\mathbf{t}_{\text {tabel }} \mathbf{1 , 2 9 6 3 2}$. Hasil penelitian ini sesuai dengan penelitian Ibriati kartika Alimudin (2012), bahwa variabel reward berpengaruh positif dan nyata.

b. Berdasarkan hasil pada uji $t$, pengaruh variabel punishment $\left(\mathrm{X}_{2}\right)$ terhadap motivasi kerja diperoleh nilai $t_{\text {hitung }} 5,040>\mathbf{t}_{\text {tabel }}$ 1,29632. Sehingga dapat disimpulkan bahwa variabel punishment $\left(\mathrm{X}_{2}\right)$ secara parsial atau terpisah berpengaruh positif terhadap variabel motivasi kerja. Hasil penelitian ini sesuai dengan penelitianSiti Febrianti (2014)sedangkan secara parsial punishment berpengruh signifikan terhadap motivasi kerja karyawan.

\section{KESIMPULAN DAN SARAN}

\section{Kesimpulan}

Berdasarkan penelitian tentang pengaruh reward dan punishment terhadap motivasi kerja di PT. Antam Pongkor, dan berdasarkan pertanyaan atas perumusan masalah bagaimana pengaruh reward dan punishment terhadap motivasi kerja karyawan di PT. Antam, Tbk UBPE Pongkor sebagai berikut:

1. Secara parsial variabel reward $\left(X_{1}\right)$ berpengaruh positif dan nyata terhadap motivasi kerja. untuk variabel punishment $\left(\mathrm{X}_{2}\right)$ berpengaruh. Variabel reward dan punishment mampu mempengaruhi variabel motivasi kerja karyawan di PT. Antam Pongkot sebesar 39,7\%, selebihnya 60,3\% dipengaruhi oleh variabel lain, diantaranya yaitu upaya, tujuan organisasi dan kebutuhan. (Stephen P. Robbin: 2001).

2. Dari hasil uji analisis pada penelitian ini bahwa ke dua variabel reward dan punishment berpengruh positif terhadap motivasi kerja karyawan di PT. Antam, Tbk.

\section{Saran}

Berdasarkan hasil penelitian, ada beberapa saran yang dapat dikemukakan sebagai bahan masukan yang bermanfaat untuk PT. Antam, Tbk.

1. Bagi PT. Antam, Tbk harus mengoptimalkan implementasi reward bagi karyawan yang berprestasi dan punishment bagi yang melakukan pelanggaran. Hal ini diharapkan dapt meningkatkan 


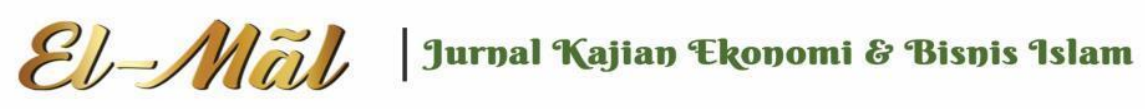

Vol 2 No 1 (2019) 70-87 P-ISSN 2620-295 E-ISSN 2747-0490

DOI: $1047467 /$ elmal.v1i1.315

motivasi kerja karyawan guna mencapai target perusahaan, sehingga timbul budaya kerja yang produktif dan memiliki integritas yang tinggi

2. Bagi penelitian selanjutnya PT. Antam, Tbk, perlu menambah metode wawancara secara mendalam untuk mengumpulkan data, sehingga meminimalisir responden yang mengisi kuesioner dengan asal-asalan dan dapat juga mengembangkan variabel independen karena ternyata masih cukup banyak faktor di luar dari variabel yang telah diteliti yang mempengaruhi varibel dependen dalam penelitian ini.

\section{DAFTAR PUSTAKA}

Abdurrahman An-Nahlawi, Pendidikan Islam di Rumah Sekolah dan Masyaakat. Jakarta: Gema Insani Press, 1995).hlm. 57.

Bacal, Robert. 2002. Performance Management. Terjemahan Surya Dharma Yanuar Irawan. Jakarta: Gramedia Pustaka Utama.

Ghozali, Imam. 2005. Aplikasi Analisis Multivariate dengan SPSS. Semarang: Badan Penerbit UNDIP.

Handoko, T.H. 2003. Pengantar Manajemen, Yogyakarta:BPFE

Handoko, T. Hani. 2003. "Manajemen Sumber Daya Manusia, Edisi 2". Yogyakarta: BPFE. Malayu, Hasibuan ,2007. Manajemen sumberdaya manusia. Jakarta: PT Bumi Akasara.

Nawawi, H. Hadari. 2005. Manajemen Sumber Daya Manusia untuk Bisnis Yang Kompetitif Yogyakarta: Gajahmada University Press

Moehoerino, 2010. Pengukuran kiner berbasis kompetensi. Bogor: Ghalia Indonesia

Muhammad Kosim, Antara Reward dan Punishment, Rubrik Artikel, Koran Kompas, Edisi Senin, 09 Oktober 2012 Hal. 1

Munandar, Ashar sunyoto (2008) .psikologi industri dan organisasi. Jakarta: Universitas Indonesia (UI- Press)

Mangkunegara, AA Anwar Prabu. 2002. Manajemen Sumber Daya Manusia Perusahaan. Bandung: PT. Remaja Rosdakarya.

Purwanto, M. Ngalim. 2006. "Ilmu Pendidikan Teoritis Dan Praktis". Bandung: Remaja Rosdakarya.

Sugiyono. (2009). Metode Penelitian Bisnis. Bandung : Alfabeta.

Rivai, Veithzal dan Sagala, Ella Jauvani. 2010. Manajemen Sumber Daya Manusia untuk Perusahaan dari Teori ke Praktik. Jakarta: PT Raja Grafindo.

Rivai, Veithzal. (2005). Manajemen Sumber Daya Manusia. PT Raja Grafindo Persada, Jakarta.

Soekanto, Soerjono. 1999. Sosiologi Suatu pengantar. Jakarta : Raja Grafindo Persada. Warson, Munawir. 1977. Kamus Al-Munawwir Arab-Indonesia Terlengkap. Surabaya: Pustaka Progresif. hlm. 373. 